\title{
Deep Diving in Search of Ecological Expertise
}

\author{
DAVID G. KENNEDY
}

Auburn University

Following Vitruvius's pedagogy, expertise in a prescribed set of disciplines is a prerequisite for the title "Architect." Far from this, a contemporary architectural pedagogy requiring only cursory engagement with satellite 'allied' fields outsources the practitioner's capacity to perform ecologically to several disassociated silos. Vitruvius's pedagogy is practically unachievable, but he offers an insight into one of its benefits, namely that the deep study of other disciplines exercises the architect's skills in adopting trans-disciplinary knowledge. An extra-disciplinary 'deep dive' trains the architect in assimilating new vocabularies and methodologies to be applied in the pursuit of ecological design.

\section{DEMAND FOR TRANSDISCIPLINARY KNOWLEDGE}

Vitruvius prerequires no less than fourteen disciplines in which one must possess expert knowledge for membership in the 'lofty sanctuary of Architecture'. These range from the innate (draftsmanship) to the exotic (medicine) and are necessarily the result of exhaustive inculcation from a young age. Making only slight concessions to this platform ("he may be no Hippocrates"), he describes two methods by which one might gain and retain such an education. For one, the similitudes between disciplines allow for productive double-dipping, i.e., measurements in geometry find an analogue in the measures of music. The second method is derivative of the first; seeking out those parallels is itself a discipline of sorts, one that enables consuming "all manner of subjects with greater ease." (22) An epistemological discipline is earned through the practice of deep study outside one's own field.

If the Ten Books on Architecture provided a broad, ambitious manifesto for the education of an architect, the NAAB Procedures for Accreditation provide a more managerial, competent take on baseline standards. For Vitruvius, the profession of architecture must be "adorned by and abundant in" the expertise of a diverse array of fields. (23) The NAAB requirements are more reluctant, requiring students of architecture to only "engage" disciplines already "allied" with architecture, or, less, to "discern the valuable roles and key players" in "relating" disciplines. (NAAB 13). The gap between these decrees can be attributed to the matured definition of the profession and the differences between ancient and contemporary practicalities. Still, the ethic of Vitruvius's pedagogy would provide a staggering, if impractical, dominion of powerful intellectual tools in the service of architecture. In contrast, our current method of cursory contact with allied fields is perhaps symptomatic of- and propagatory to the retreat of architecture from much of the activities in forming buildings, cities, and landscapes. This may be exacerbated by the growing list of disciplines to which we feel we should be allied and make occasional, isolated forays. Vitruvius's list of fourteen would now surely grow to include computation, carbon science, media studies, and social justice, to name a few, and the gap between multivalent expertise and fleeting engagement grows commensurately. The irony of this is in the fact that it is arguably more critical to have deep, transdisciplinary knowledge now than in the time of Augustus. Our globalized world inextricably binds disciplines through reciprocity and co-dependence, and the stakes of this critical network grow as a picture of humanity's fragility clarifies. Through our participation in the formation of buildings, cities, and landscapes, we are complicit collaborators in crafting a tenuous web of material, energy, and culture flows.

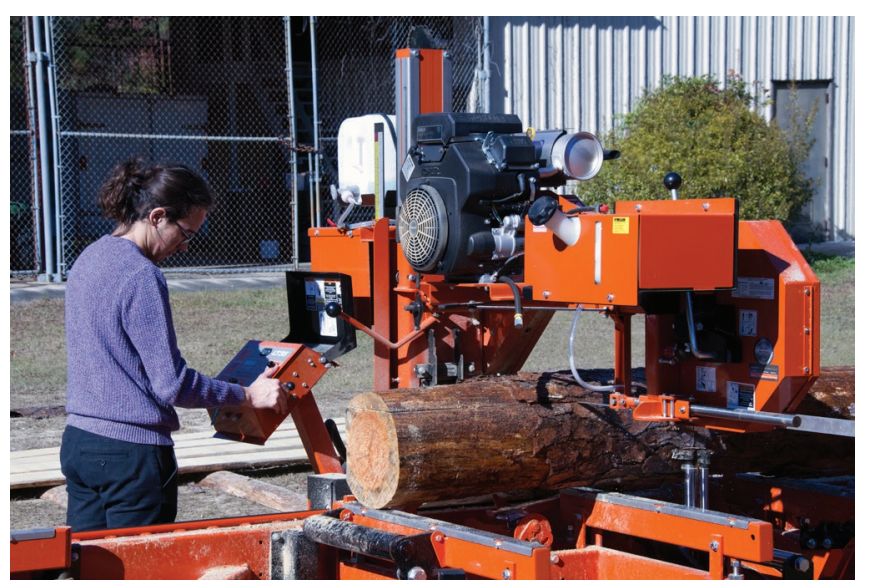

Figure 2: 3 Students operated a portable sawmill to create lumber from a Loblolly Pine log

To navigate this ecology, students and practitioners of architecture engage other fields and develop relationships through empathy and commonalities. The objective of these relationships is to extract knowledge for use in advancing architectural agendas. And the vehicle for these relationships is the assumption of vocabularies and methodologies from the fields lending knowledge. These are adopted to the extent that an express quantity and depth of knowledge is minimally required for the architectural project; we will 'speak the language' of contractors insomuch as it is necessary for the work's execution. This stands in stark contrast to Vitruvius's ambitions for transdisciplinary knowledge and 
obviates the possibilities for capitalizing on parallels between disciplines and exercising the architect's skills in assimilating an ever-broadening information set. His polymathy-as-prerequisite, however, is not tenable. Still, a pedagogy based in even a few extra-disciplinary 'deep dives' can achieve the latter, bolstering the student's or practitioner's capacity to form a more powerful understanding of their own discipline. These non-expert forays require taking the time to understand the vocabularies and methodologies of other disciplines well beyond what is immediately or obviously required. Concentrated, narrow study develops a robust, albeit temporary, expertise. Even if this fleeting residency may not promote the retention of a peculiar discipline's vocabularies and methodologies, the exercise of it permanently strengthens a student's epistemological discipline.

\section{DIVING INTO MASS TIMBER}

Translating this pedagogy to curriculum requires defining a relatively narrow scope of study to ensure that deep dives are not without some relevant frame of reference. The pedagogy I put forward centers on the study of mass timber construction technologies. The reasoning behind this is threefold: it is an expanding field for which young designers should be equipped, it is an indeterminate field that obliges further architectural study, and it is an inherently transdisciplinary field, slicing a broad cross section across the various scales it affects. The curriculum for this study is embodied in two courses: a comprehensive, undergraduate, fourth-year design studio and an upper level, undergraduate seminar. In their first iteration, the courses, Building Tall with Wood and Mass Timber Workshop, were taught as co-requisites with an overlapping cohort. In their second iteration, the same courses are taught in series rather than parallel. The Fall 2018 Mass Timber Workshop serves as a basis for the Spring 2019 Building Tall with Wood studio. In both courses, mass timber is examined for its extensive and intensive properties as they relate to morphology, thermodynamics, and socioeconomics. (DeLanda 6). Neither course devotes significant attention to mass timber as a structural material beyond a cursory study in orders of magnitude. The intent is rather to shift focus away from the scale of building structures and towards the perimeter scales of material anatomy and territorial impact. Shifting scales situates students in unfamiliar territories occupied by other disciplines, e.g., botany and rural sociology, and precipitates the uptake of new vocabularies and methodologies.

To make these deep dives more productive, and to prevent them from being prohibitively foreign, students are armed with familiar tools. Trained on new fields, the skills they have gained as upper-level undergraduates produce new meanings. The students produce "orthographic projections" of wood species' cellular anatomy, "shop drawings" of the regional impacts of forestry, and "site models" of timberland ownership patterns.

\section{SHIFTING SCALES, SHIFTING DISCIPLINES}

In perhaps the most intensive of deep dives, students examined the underlying geometries responsible for imparting performance characteristics on wood species. Bookended with lectures by professor emeriti wood anatomists, Workshop students immersed themselves in a Scanning Electron Microscope (SEM) lab to analyze a wide array of species for their cellular morphology. Critical to this is an understanding of the vocabularies and methods of wood anatomy diagnosis and SEM imaging.

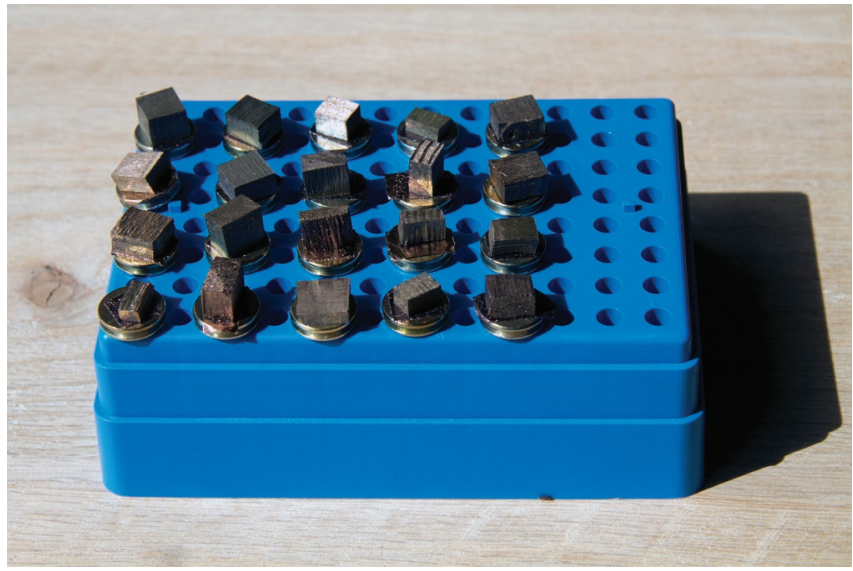

Figure 2: Gold-coated wood samples prepared for the SEM

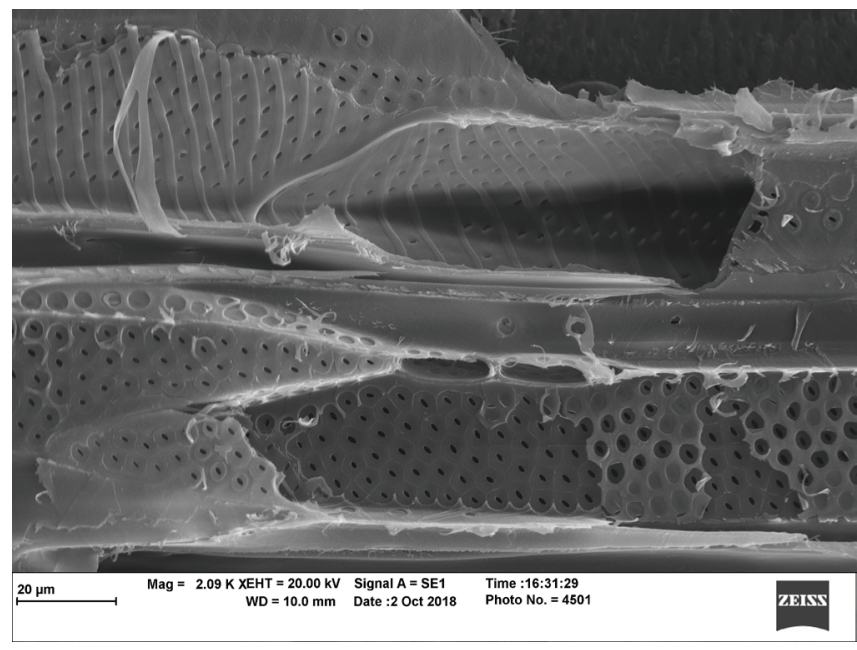

Figure 3: Basswood, as identified by a student with scanning electron microscopy

Navigating the microscope, students analyzed species samples as they would a precedent building, city, or landscape, identifying characteristics of structure, hierarchy, ordering, and growth. In the language of wood anatomy, they describe how those geometries contribute to the functionality of the tree and its derivative wood. These functions include the transport of water and nutrients, the isolation of air, and the development of a resilient anisotropic 
structure. To communicate the wood's morphology and functionality, the students retreat to skills developed from their own disciplinary pedagogy: photography, orthographic projection, and physical modelling. In a triptych format, an SEM image, a third angle projection drawing, and a low-relief model describe their new understanding of a design precedent and how it might be deployed in the formation of mass timber.

Shifting scales, another deep dive situated students in the broader regional economy. Lectures from two rural sociologists, two foresters, two forests products industry representatives, and one certifier provide an intellectual basis to understand the scope of interests potentially impacted by an expanded mass timber industry. To better develop empathy with the forest products industry and learn its vocabularies and methods, students engaged with one of its quintessential exercises - commoditization of trees.

Given Loblolly pine logs, students are tasked with extracting value by operating a portable sawmill. The most efficacious extraction is dependent upon the determination of a system boundary. Systems that consider speed of production, waste quantity, and product stability, for

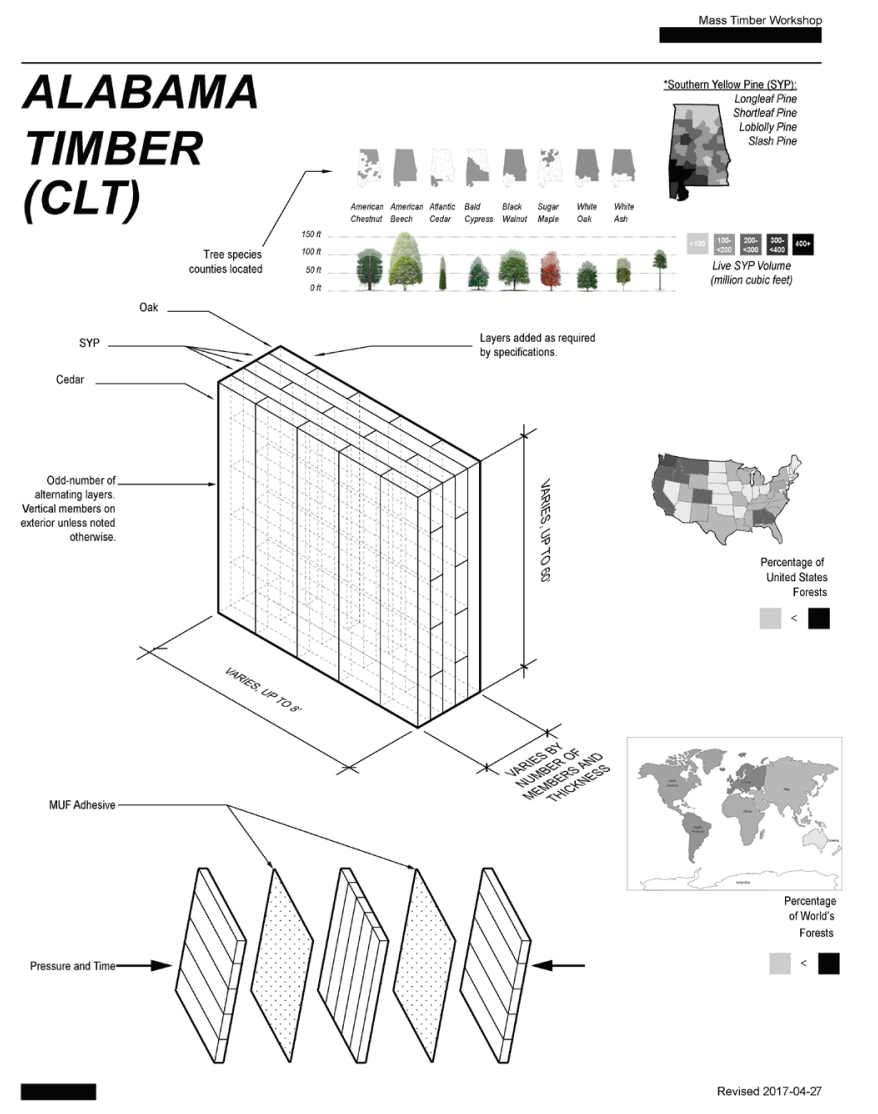

example, will precipitate more complex decision-making criteria. Operation of the sawmill forms those decisions into a physical process and commodity. Operation imbues a haptic understanding of commoditization, and, coupled with the previous intellectual understanding, students are tasked with designing mass timber products that address the socio-economic impacts that cascade from any forest products endeavor, including the production of mass timber. As with the wood anatomy exercise, students rely on familiar skill sets from their own discipline. Here, they create 'shop drawings'. These artifacts describe a design object for fabrication, but that description includes an elucidation of the trans-scalar processes that led to the capacity to form this commodity.

These shop drawings branch into two iterations. The first is physical; a full-scale sample is constructed with industrystandard techniques, including hydraulic pressing and nail lamination. This sample maintains the material morphology of the shop drawing, giving form to the ideas it embodies. The second is projective; the new commodity is integrated into the comprehensive studio project. In this new material and thermodynamic milieu, the commodity can be evaluated for its transferability.

\section{Timber Thinning Panel}

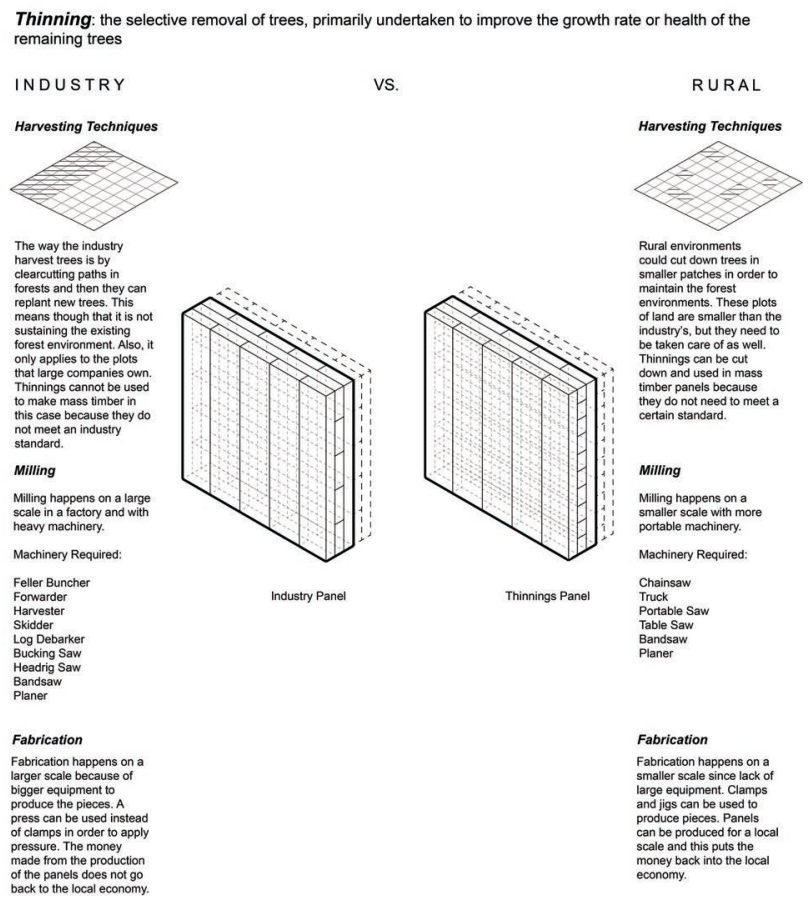


Two deep dives, into the realms of the cellular and the economic, exercise students' capacity to internalize the critical vocabularies and methodologies of disciplines outside their own. This contrasts with the orthodoxy of building technology pedagogy, which largely parallels the normative and outmoded practices of the profession. Being ecological requires trans-disciplinary comprehension deeper than cursory consultations and broader than current alliances allow. For building technology pedagogy to prepare designers to navigate an increasingly complex ecological web of global flows, it will need to acknowledge the trans-scalar, extrinsic and intrinsic characteristics of the materials and system we employ. Mass timber provides a clear example and fruitful territory to explore a more powerful building technology approach. As a material it is simultaneously structure, enclosure, assembly, and ecological artifact. As a product of our period, it is formed by factors social, economic, scientific, technical, and ethnological, and mass timber design is not easily siloed in contemporary building technology practice and pedagogy. (Gideon 19). In Vitruvius's estimation, the architect should be well equipped to address a diffusion of challenges with competency. Perhaps now, with a more singular ecological imperative, our building technology pedagogy can form young designers exercised to anticipate the challenges and opportunities of a trans-scalar, trans-disciplinary, holistic approach to design.

\section{REFERENCES}

Deleuze, Gilles, and Félix Guattari. A Thousand Plateaus. Minneapolis, MN: University of Minnesota Press, 2007.

Delanda, Manuel. MATTER MATTERS. Centro Multimedia. cmm.cenart.gob.mx/ delanda/textos/matter.pdf.

Giedion, Sigfried. Space, Time and Architecture: The Growth of a New Tradition. Cambridge, MA: Harvard University Press, 2008.

National Architectural Accrediting Board. "Procedures for Accreditation." NAAB, 2015.

Vitruvius. Vitruvius: Ten Books on Architecture, eds., Ingrid Drake Rowland and Thomas Noble Howe. Cambridge, UK: Cambridge University Press, 2001. 